\title{
The Role of Audience Comments in YouTube Vlogs: An Abstract
}

\author{
Devdeep Maity and Margot Racat
}

\begin{abstract}
One highly regarded platform of social media is a video blog or a vlog. A vlog uses video as its communication medium. The content of such vlogs may range from product or service reviews, trending news, entertaining celebrity gossips, travel, unboxing, gaming, how to videos and much more. The paper specifically focusses upon YouTube as a vlogging platform, which is a popular video-sharing website that enables its users to create and upload videos.

Companies wishing to get their brand or product brought up in vlogs most commonly offer vloggers products or services for free, gift cards or money (Liljander et al. 2015). In exchange, the vloggers provide positive and interesting content about the products or services on their vlogs (Liljander et al. 2015). However, the effectiveness of such vlogs and the reputation of the vlogger may be seriously undermined or strengthened by viewers who leave a trail of negative or positive comments, respectively, in relation to the posted content. Despite its relevance and importance, scholarship that focusses upon the impact of comments on the effectiveness of endorsements in the context of YouTube vlogs is understudied. The present study investigates the interactive effect of the valence of audience comments and perceived credibility of the vlogger (PCV) on the attitude of the viewer towards the endorsed brand (BA). The study further explores if such comments are by one vs. multiple viewers and if there exists a dyadic interaction between the commentator(s) and the viewer and its role in moderating the PCV-BA relationship. Several propositions are presented along with a proposed methodology.
\end{abstract}

D. Maity $(\bowtie)$

Delaware State University, Dover, DE, USA

e-mail: dmaity@ desu.edu

M. Racat

EDHEC Business School, Roubaix, France

e-mail: Margot.racat@edhec.edu 